\title{
De la palabra a la acción: \\ Oradores, editores, abogados y conspiradores en el virreinato del Perú, 1780-1808
}

\author{
por \\ Mónica Ricketts \\ Assistant Professor, Department of History, Temple University
}

\begin{abstract}
El artículo analiza la transformación de los hombres de letras en actores políticos en el virreinato del Perú durante los años 1780-1808 con el fin de contribuir a la discusión sobre la irrupción del liberalismo en el mundo hispánico. Un aspecto fundamental en este proceso, aunque menos atendido por la historiografía sobre el tema, fue la aparición de nuevos actores políticos durante la primera era liberal de las Cortes de Cádiz (1810-1814). Este no fue un hecho súbito, sino el resultado del largo proceso de reformas borbónicas, durante el cual la Corona promovió el surgimiento de un nuevo tipo de oradores, escritores y abogados, a quienes encomendó la tarea de modernizar las costumbres y la administración. Lo que la corona no alcanzó a prever es que estos mismos individuos pudieran alzar sus voces individuales en público, criticar formas de gobierno e imaginar nuevos órdenes sociales que los llevaran al poder.

Palabras clave: Perú; España; Ilustración; hombres de letras; politica.
\end{abstract}

\section{INTRODUCCIÓN}

Desde el temprano siglo XVIII, las autoridades reales auspiciaron el surgimiento de una meritocracia que pudiera modernizar la administración y gobernar tanto España como el imperio de manera eficiente. Con este fin, la Corona promovió la formación de burócratas profesionales y subordinados que trabajaran por la consolidación del poder real ${ }^{1}$. A los hombres de letras les

\footnotetext{
${ }^{1}$ Para un análisis de las relaciones institucionales y personales gestadas a lo largo del siglo XVIII a través de la producción textual, manuscrita e impresa, y para advertir cómo el
} 
correspondería un lugar central en estos planes. Los abogados serían educados en las mejores escuelas, reformadas y controladas por el gobierno central, y se encargarían de elaborar leyes e implementarlas, mientras que los escritores y profesores se ocuparían de diseñar y llevar a cabo una ambiciosa reforma moral e intelectual en universidades, academias, teatros y otros espacios públicos. De este modo, estos leales y profesionales hombres de letras liderarían la batalla contra los privilegios establecidos por la dinastía Habsburgo que, según la ideología borbónica, habían sumido en el atraso al imperio español. Lo que la Corona no alcanzó a prever es que estos mismos hombres de letras pudieran actuar de manera independiente y convertirse en individuos con voces propias, escribir y protestar en público, proponer nuevos órdenes sociales y encabezar conspiraciones.

Entre 1780 y 1808, algunos hombres de letras, influidos por la Ilustración y un incipiente liberalismo, comenzaron a demandar respeto y poder. Consideraban que su conocimiento y capacidad crítica los había transformado en hombres virtuosos y, por ende, en autoridades. Sin embargo, la realidad no cambió al ritmo de sus expectativas. Las reformas borbónicas enfrentaron sus peores derrotas en el campo educativo y cultural y los hombres de letras se vieron obligados a abrirse un espacio propio en los aún tradicionales ámbitos de la Universidad y la Iglesia. La falta de oportunidades los llevó a chocar, tanto con las autoridades tradicionales como con sus pares, al tiempo que sus escritos y discursos se alejaron de las utopías y se volcaron al debate y lucha por el poder. En tales enfrentamientos, estos nuevos hombres de letras alteraron su papel en la sociedad, así como la forma tradicional de hacer política.

Hasta entonces la política - en tanto debate sobre el arte de gobernar y lucha por el poder - había sido una actividad restringida a grupos cerrados vinculados a la Corte, la Iglesia y las universidades. El pueblo podía expresar sus opiniones a favor y en contra de autoridades específicas por medio de protestas durante ceremonias y espectáculos. Algunos podían incluso arriesgarse a pegar pasquines clandestinos en las puertas de las iglesias, por ejemplo, pero no estaba permitido debatir en público, criticar formas de gobierno, ni mucho menos cuestionar la legitimidad o el grado de virtud de ciertas autoridades. La política era — en palabras de Robert Darnton - una actividad secreta ${ }^{2}$.

En las últimas décadas, la historiografía política y cultural sobre la independencia en Hispanoamérica se ha centrado en la llamada «revolución hispánica». De acuerdo a esta línea interpretativa, la invasión napoleónica de 1808

arte de la pluma devino en un recurso altamente valorado, ver Peralta, 2006: 34-60. Para una historia del Perú durante la era borbónica ver Fisher, 2000.

2 Darnton, 2010, caps. 22 y 23. 
provocó un trastorno tal que socavó irremediablemente las bases del Antiguo Régimen. Para François-Xavier Guerra la modernidad irrumpió de pronto junto con Napoleón en el mundo hispánico provocando mutaciones culturales que, como el surgimiento de nuevos espacios de discusión política, establecerían en los territorios americanos los fundamentos de lo que sería primero una lucha por la autonomía y luego por la independencia ${ }^{3}$. Por su parte, Jaime E. Rodríguez O. y Brian Hamnett han sostenido que la invasión napoleónica desató más bien una revolución constitucional o liberal en el imperio español al imponer nuevas ideas y prácticas políticas como los procesos electorales ${ }^{4}$.

Este trabajo concuerda con los autores anteriores en valorar el enorme impacto que tuvo la invasión napoleónica, sin la cual los futuros cambios políticos se hubieran dado de manera mucho más lenta y la independencia hubiera tardado quizás décadas en producirse. Sin embargo y en discrepancia con Guerra, el trabajo argumenta que muchas de las transformaciones que se hicieron evidentes durante la era liberal de Cádiz, como el surgimiento de nuevos actores políticos, tuvieron larga data y obedecieron en gran medida a los intereses borbónicos de reformar y modernizar el imperio. Por ello, si estudiamos las luchas políticas de estos años, no sólo a nivel de ideas teóricas, sino en tanto debate y lucha por la autoridad y el poder, podemos observar que en el tardío siglo dieciocho, algunos hombres de letras se habían transformado ya en actores políticos modernos. Es por ello que cuando las Cortes se reunieron en Cádiz para diseñar el futuro liberal del imperio en 1810, los oradores y abogados asumieron roles protagónicos. Rápidamente llevaron sus debates a la prensa, que en este contexto se convirtió en un espacio privilegiado de expresión. Así surgieron los panfletistas, entregados a la conquista de la opinión pública ${ }^{5}$ Y Y así también, en los tumultos de estos años, aparecieron los conspiradores, quienes, creyendo en su autoridad individual, se aventuraron a imaginar y diseñar nuevos órdenes sociales que los llevaran al poder.

Con el fin de analizar esta transformación fundamental en la vida política del virreinato peruano, el texto se centrará en los nuevos roles asumidos por los hombres de letras. En orden sucesivo se analizará a oradores, escritores y editores, abogados y conspiradores. Debido a las limitaciones de espacio, la argumentación se basará en algunos ejemplos específicos del caso peruano, como el escándalo producido por el discurso de José Baquíjano y Carrillo en 1781, las disputas entre los editores de los tres primeros periódicos limeños

3 Guerra, 1992.

4 Rodríguez, 1998. Hamnett, 1997.

5 Para el surgimiento de nuevos espacios y formas de expresión en España y el Perú durante el primer liberalismo de las Cortes de Cádiz ver Seoane, 1977. Chassin, 1998. 
en 1791 y el intento de conspiración de Gabriel de Aguilar y Manuel de Ubalde en 1805. Y como la transformación política aquí descrita no fue un hecho particular de este virreinato, el análisis intentará — en la medida de lo posible - situar la discusión en un contexto imperial más amplio a través de alusiones a la metrópoli.

DE PANEGIRISTAS A ORADORES

El prototipo de hombre de letras en los siglos XVI y XVII había sido el letrado. Este término describía a aquellos individuos que ocupaban cargos administrativos en una ciudad o Corte $^{6}$. Se trataba fundamentalmente de abogados, burócratas, regidores, oidores y notarios, en cuyas manos quedaba, a decir de Ángel Rama, la administración imperial de las ciudades ${ }^{7}$. Los letrados podían desempeñarse también como escritores y oradores, siempre y cuando tuvieran acceso a una Corte que los proveyera de comisiones y patrones, pues la independencia profesional no era una condición bienvenida ${ }^{8}$. Incluso durante el Siglo de Oro, cuando se produjo un auge cultural en las capitales peninsulares y americanas que provocó una gran demanda de dramaturgos y poetas, los escritores desdeñaron el camino individual. Aún para Lope de Vega, el escritor más exitoso y prolífico del mundo hispánico, depender del gusto del «vulgo» implicaba una posición degradada, de mucha angustia y reducido placer?.

A los escritores cortesanos les correspondía entretener con sus comedias y dramas, así como encomiar a las autoridades con sus panegíricos. En aquel ambiente y durante el apogeo del barroco en el siglo XVII, el género discursivo por excelencia era la oratoria sagrada. Como lo ha sostenido José Antonio Rodríguez, este tipo de discurso suponía una forma de expresión complicada y severamente regulada. El panegirista debía conmover y demostrar con su elocuencia el dominio del latín, la filosofía escolástica y el complicado estilo barroco cargado de alegorías y ornamentos ${ }^{10}$. No se esperaba que su discurso fuera entendido por todos, sólo por unos cuantos iniciados. Su meta no era convencer, sino impresionar.

${ }^{6}$ Diccionario de la Real Academia de la Lengua (RAE), 1734.

7 Rama, 1996: 18.

${ }^{8}$ Peralta, 2006: 26.

9 Gilbert-Santamaría, 2005, cap. 1.

${ }^{10}$ Rodríguez Garrido, 2000: 249-265; sobre la relación entre oratoria sagrada y sermones véase 1992: 115-129. Para el caso de Francia y del rol de las escuelas jesuitas ver el texto clásico de Fumaroli, 1980. 
Por lo general, los panegíricos eran ofrecidos en actos semi-públicos ante una audiencia selecta. En Hispanoamérica era usual escucharlos durante ceremonias civiles, como el recibimiento de un virrey por los diferentes cuerpos de la sociedad o durante funciones religiosas o certámenes universitarios. Estas ocasiones ofrecían oportunidades ideales para que los letrados desplegaran sus talentos y encontraran el favor de un buen patrón. En estos actos, la audiencia esperaba que los oradores hablaran en representación de cuerpos sociales específicos como la Universidad y la Iglesia. Sus voces no eran individuales, ni el público aludido era el pueblo. No fue sino hasta mediados del siglo XVIII en Francia, como apunta Paul Friedland, cuando se comenzó a hablar en voz alta ante un público general y abstracto ${ }^{11}$.

En el imperio español, como en muchas partes del mundo occidental, el papel de la oratoria empezó a cambiar por aquellas fechas. Esto se debió en gran medida a la propagación de la estética neoclásica que proclamaba la claridad, didáctica y el realismo como nuevos objetivos de la producción artística $^{12}$. Pero también se debió a los esfuerzos de la corona borbónica, que desde el temprano siglo XVIII hizo suyos estos ideales estéticos y culturales con el fin de modernizar las tradiciones y rituales. En su lucha por la preeminencia del poder civil sobre el religioso, las autoridades reales auspiciaron el control de las tradiciones populares y la promoción de un nuevo estilo claro y simple que sirviera a sus propósitos ${ }^{13}$. Estas campañas fueron reforzadas con los proyectos de reforma educativa en los que se promovieron cursos de enseñanza práctica y útil. Poco a poco los certámenes de matemáticas y leyes fueron suplantando a los antiguos certámenes poéticos, mientras que los exámenes universitarios se convirtieron en eventos semi-públicos en los que los candidatos debían mostrar sus conocimientos, méritos y manejo de la nueva oratoria ${ }^{14}$. En el virreinato del Perú, las élites de Lima, siempre afanadas por comportarse de acuerdo a los usos de la Corte en Madrid, pronto hicieron suyos estos nuevos usos y empezaron a circular invitaciones para los certámenes académicos de sus hijos ${ }^{15}$.

11 Friedland, 2002: 33-34.

12 Ibidem, 21. Véase también cap. 2.

13 Estenssoro, 1992a y 1992b. Para el caso de México ver Viqueira 1987, cap. 3.

${ }_{14}$ Por ejemplo: Certamen ò conclusiones matemàticas, 1768. Certamen publico de derecho natural, politica y derecho, 1788. Para una descripción de los certámenes antiguos véase Williams, 1994: 55-56.

${ }^{15}$ La colección Moreyra del Archivo General de la Nación (AGN) en Lima contiene una pequeña colección de invitaciones para oposiciones, licenciaturas y exámenes doctorales. Por ejemplo, el anuncio de la disertación de José Joaquín de Olmedo decía así: «Don Antonio Izquierdo Martinez, Administrador General de esta Real Aduana, le suplica se sirva concurrir 
En estas circunstancias de grandes reformas y cambios, la elocuencia cobró un sentido nuevo y fue lentamente vinculándose al discurso político. Así, los panegiristas se transformaron en oradores políticos, que aspiraban a distinguirse del orador cortesano y barroco. Inspirados en los ejemplos de la Roma clásica, estos nuevos oradores ya no aspiraban a entretener, sino a persuadir. Las autoridades borbónicas alentaron este giro, pues les convenía que la oratoria sirviera a los intereses reales y a la reforma de la sociedad. Por ello y con el fin de que los estudiantes aprendieran a exponer sus ideas con claridad para persuadir a sus opositores, la Corona auspició la publicación de manuales de elocuencia en la metrópoli. Estos textos explicaban las reglas de composición y los diferentes tonos declamatorios, pero también describían el poder insuperable de la elocuencia. Por ejemplo, en 1750 un epítome o compendio sobre el arte de hablar y argumentar con elegancia sostenía que los fines de la elocuencia eran tres: «deleytar, persuadir y disuadir... en pulpito, escuela, ó plaza». Pues, como argüía su autor, la elocuencia era «tan eficaz, que logra lo que no pueden las armas, razón, pleitos ni justicia». Ella:

concilia amigos;/ Esta un gran furor aplica;/ Esta suspende un castigo;/ Esta humilla una arrogancia/ A esta suelta el que es avaro; Á esta la mujer resvala; Á esta se aplaca un motin;/ Á esta se rinde un Monarca./ Y en conclusion de sus fuerzas,/ Todo quanto hai avasalla:/ Sin ella nada se logra,/ Con ella todo se alcanza./ Es tan util, como al mundo/ Son Letras, y Armas, pues pasa/ A ser Elocuencia en Letras,/ Lo que es destreza en las Armas ${ }^{16}$.

Estas explicaciones coincidían con las ideas propagadas por los philosophes en la Encyclopédie ou Dictionnaire Raisonné des Sciences, des Arts et des Métiers. En 1755 sus lectores se enteraban del nuevo rol político que según Voltaire correspondía a los discursos en «Las Luces» (Les Lumières). En su ensayo sobre la elocuencia, el filósofo francés sostenía que ésta era una expresión de libertad y que por lo tanto había muerto al derrumbarse la república romana. Un arte semejante sólo podía florecer en una asamblea grandiosa como el parlamento inglés, añadía el filósofo. Al carecer de un espacio similar en Francia, la elocuencia había tenido que refugiarse en la poesía, las oraciones fúnebres y el púlpito. Sin embargo, Voltaire esperaba que

el sabado 19 del corriente á las 4 de la tarde, á la Real Universidad de San Marcos á la Leccion que sobre la catedra de Artes ha de pronunciar su Pariente Don Jose Olmedo, alumno del Real Convictorio de San Carlos, favor á que quedare reconocido». Baquíjano también envió invitaciones a la «lectura que hace á la cátedra de sagrados cánones: cuyo favor espera y agradecerá» AGN, Colección Moreyra, Miscelánea, D. 1, 104-105, n. d.

${ }_{16}$ Artiga, 1750: 47. 
«el mundo ilustrado» recuperara el verdadero sentido de la oratoria expresado en los discursos de los senadores romanos ${ }^{17}$.

La transformación del género barroco de la oratoria sagrada en un arte cívico de estilo neoclásico estuvo acompañada por el dramático surgimiento de los discursos políticos ${ }^{18}$. El primer discurso de este tipo pronunciado ante una audiencia semi-pública en el Virreinato del Perú fue el ofrecido por José Baquíjano y Carrillo en Lima en agosto de 1781. Ese día los profesores, autoridades y la élite de la ciudad se congregaron en la Universidad de San Marcos para dar la bienvenida al nuevo virrey, Agustín de Jáuregui (17801784). De acuerdo a la tradición, el elogio de bienvenida al virrey debía estar a cargo de uno de los catedráticos más prestigiosos. Baquíjano era el más joven en la universidad, pero también el más rico. Además pertenecía a la alta nobleza ${ }^{19}$. Sus palabras simbolizarían la alianza entre la monarquía y las élites del Perú.

Con el ímpetu de un hombre de letras poderoso y joven, recién llegado de la metrópoli para ocupar los altos cargos de fiscal interino del crimen, protector de indios y catedrático de Instituta y Vísperas de Leyes, Baquíjano asumió el reto de desafiar a su audiencia. Si bien el Elogio del excelentísimo Señor Don Agustín de Jáuregui y Aldecoa siguió las pautas tradicionales de comenzar por encomiar las virtudes del nuevo gobernante, el tono, contenido y citas eran los de un discurso político moderno. Baquíjano estaba al día con las transformaciones políticas y culturales que experimentaban España y Francia y ya no se contentaba con el rol de panegirista «que infama al otro perpetuando el oprobio de su adulación». Se concebía más bien como un orador en el sentido romano, luchando por la virtud y la verdad. Pues como él sostenía:

La gloria y la inmortalidad, señor excelentísimo; esa sólida recompensa del Héroe; esa vida de honor que anima en el sepulcro a sus cenizas; esa memoria augusta de su nombre, no se afianza ni apoya en los elogios e inscripciones públicas que le consagran y tributan la dependencia y el temor... La verdad, sacrificado su pudor, se retira en el duelo y la amargura; espera en esta angustia a que el tiempo restaure sus sagrados derechos, y que destruido el ídolo, le fabrique el trono de los siglos futuros. Entonces con placer rompe las cadenas que la tienen cautiva; vuela a ocupar el solio de su imperio, y tomando en mano la incorruptible balanza, cita

17 Véase Voltaire, 1755. Sobre la circulación de la Encyclopédie entre las élites peninsulares y americanas véase Spell, 1938: 220, 226-227. Para España véase Herr, 1958, caps. 3 y 7. Para el Perú, Rosas, 2006.

${ }_{18}$ Para las historias de Inglaterra y Francia sobre este respecto ver Friedland, 2002, cap. 2. Hunt, 1986. Brewer, 1981, cap. 9.

19 Burkholder, 1980: 19. Colección Documental de la Independencia del Perú (CDIP), tomo I, 3, 1974: XI-XV. Sobre Baquíjano ver también De la Puente Brunke, 1995. 
a su tribunal del mérito; pondera en éste la de los aplausos, y en un mismo decreto desautoriza al uno degradando la falsa grandeza, e infama al otro perpetuando el oprobio de su adulación ${ }^{20}$.

Baquíjano dedicó su discurso a reclamar la necesidad de un gobernante justo y virtuoso y a criticar a las autoridades por la brutal represión de la rebelión de Túpac Amaru, ocurrida tres meses antes ${ }^{21}$. La crítica más fuerte y controversial del discurso estuvo dirigida al visitador Antonio de Areche, quien desde un palco en el teatro de la universidad escuchó declamar al joven profesor y advertirle al virrey que reconociera la lealtad de los súbditos americanos y se cuidara de los intrigantes. También le recordaba la necesidad que tenía todo príncipe de rodearse de hombres virtuosos para evitar corromperse ${ }^{22}$. Pues la primera obligación de un gobernador - añadía - debía ser inculcar el amor del pueblo hacia su soberano ya que éste es como «un resorte, que forzado más de lo que sufre su elasticidad, revienta destrozando la mano imprudente que lo oprime y sujeta» ${ }^{23}$.

Como era habitual, el Elogio de Baquíjano se publicó inmediatamente después de la ceremonia. En la edición impresa, el joven profesor de leyes desplegó su erudición con numerosas citas de Séneca, Tácito y Las Casas, pero también con referencias a autores y textos prohibidos como la Encyclopédie, Marmontel, Raynal, Montesquieu e, indirectamente, Maquiavelo. En las notas a pié de página, Baquíjano incluyó ejemplos de estos autores para ilustrar sus críticas, lo que enfureció al visitador Areche. Y así, en el clímax del Elogio, cuando aconsejaba al nuevo virrey atesorar la lealtad de sus súbditos americanos y cuidarse de los intrigantes, Baquíjano citó un ejemplo de las Cartas Persas de Montesquieu en que el filósofo francés contaba el drama del rey Carlos XII de Suecia, alejado de sus súbditos por una calumnia ${ }^{24}$. Otro ejemplo tomado de la Histoire Philosophique de Raynal describía cómo en una remota provincia de la China, un pueblo inocente había sido severamente

${ }^{20}$ Elogio al virrey Jáuregui por Baquíjano en la Universidad de San Marcos, Lima, 27 agosto 1781. CDIP, I, 3, 1974: 65-66.

${ }^{21}$ La rebelión de Túpac Amaru escapa al tema específico de este trabajo. Como lo ha demostrado Scarlett O'Phelan, ésta fue una rebelión contra el mal gobierno directamente relacionada con las reformas borbónicas fiscales y administrativas. Túpac Amaru no fue un líder político de estilo moderno interesado en proclamar su autoridad y crear un nuevo orden. Ver O'Phelan, 1988. Para contextualizar el periodo y entender la rebelión en el contexto del gobierno de Jáuregui y la visita de Areche, ver también, Moreno Cebrián, 1977.

${ }^{22}$ Elogio al virrey Jáuregui por Baquíjano en la Universidad de San Marcos, Lima, 27 agosto 1781, CDIP, I, 3, 1974: 65-66.

23 Ibidem: 88-89.

${ }^{24}$ Ibidem: 85. 
castigado por protestar contra un mandarín injusto, viéndose así alejado del amor a su soberano ${ }^{25}$.

Tras ver su autoridad cuestionada y satirizada en un acto público primero y luego en un impreso, Areche reportó el escándalo al ministro José de Gálvez en Madrid, acusando al nuevo virrey de consentir el descrédito en público de los oficiales reales ${ }^{26}$. Tres semanas después, el visitador escribió otra carta a Gálvez detallando el incidente y remitiéndole copias impresas del Elogio. Sus agitadas frases revelan todo aquello que resultaba nuevo y por lo tanto alarmante para las autoridades reales. ¿Cómo era que las autoridades permitieran discursos como estos contra los ministros del rey en el teatro de la universidad?, ¿y cómo se podía dejar que los limeños leyeran textos prohibidos?, preguntaba el visitador ${ }^{27}$. Acto seguido, Areche solicitó un permiso real para reprimir a los letrados, alegando que: «Si esto hacen, piensan y escriben los letrados, los instruidos o los que deben estar y no lo están, ¿qué esperamos señor de sus bocas sino blasfemias? Dios ilumine al rey y a vuestra excelencia para tomar los medios para acallarlos $\rangle^{28}$. Sus demandas fueron atendidas y en 1783 un decreto real ordenó la confiscación del Elogio ${ }^{29}$.

El caso de Baquíjano suscitó un debate político público. Frente a esta nueva realidad en la que las autoridades reales se veían cuestionadas por escrito, el visitador decidió defender su honor también con un impreso y encargó una Refutación. Esta se publicó en Buenos Aires y fue elaborada por el sacerdote Juan Baltasar Masiel, doctor en derecho civil y canónico, consejero del virrey de la Plata y director del colegio de San Carlos en Buenos Aires. Masiel era un orador erudito. Las ciento setenta páginas de la Refutación intentaron rebatir cada premisa del Elogio. Al parecer, lo que más había indignado a Areche era el haber sido comparado con los déspotas chinos descritos por Montesquieu en las Cartas Persas. ¿Cómo era posible, anotaba Masiel, que:

...un fiscal protector de la primera Real Audiencia de estos reinos, y un catedrático de leyes de su más acreditada Universidad, títulos con que se condecora su mérito en el frontispicio del panegírico, hace valer una ley de la China, obra del

25 Ibidem: 89.

${ }^{26}$ Carta de Areche a Gálvez con noticia sobre el «Elogio»y de los «parlamentos» con los caciques propuestos por Jáuregui, Lima, 3 de noviembre de 1781 (fragmento), CDIP, I, 3, 1974: 182-83.

27 Carta de Areche a Gálvez sobre la intención crítica y política del «Elogio» y su referencia a cuestiones del momento, Lima, 22 noviembre de 1781, CDIP, I, 3, 1974: 192-194.

28 Ibidem: 196.

${ }^{29}$ Real Orden reservada mandando recoger los ejemplares del «Elogio» escrito por Baquíjano (minuta), Madrid. 1 de agosto de 1783, CDIP, I, 3, 1974: 215. 
despotismo y de una autoridad imperiosa, que reconcentrada en las espesas tinieblas de su gentilidad, no reconoce otros principios que los caprichos de su voluntad ${ }^{30}$ ?

El discurso de Baquíjano condujo también a una investigación sobre la circulación de literatura subversiva y a una renovación de los esfuerzos por controlar la expresión escrita. Las autoridades implicadas presentaron al ministro Gálvez en Madrid suficientes explicaciones para salvar sus responsabilidades. Según su informe, la Aduana en Lima carecía de espacio para almacenar los libros importados hasta que la Inquisición los inspeccionara. Por lo tanto, éstos eran enviados directamente a los destinatarios y/o terminaban siendo vendidos sin los controles pertinentes. En 1785, el virrey Teodoro de Croix (1784-1790) ordenó solucionar de inmediato este problema pero encontró grandes trabas ${ }^{31}$. La universidad gozaba de un privilegio antiguo que le permitía publicar las obras de sus miembros sin la aprobación del censor, como ocurrió en el caso de Baquíjano. Pese a los precedentes, en 1786 el virrey Croix abolió el privilegio y dispuso que toda obra a ser impresa contara con una licencia real ${ }^{32}$. En cuanto a Baquíjano, tras asistir a la purga de su biblioteca, escribió un memorial de arrepentimiento al rey, ofreciéndole su subordinación absoluta en el futuro, promesa que supo cumplir ${ }^{33}$.

Lima no experimentó más escándalos de este tipo en los últimos años del siglo XVIII. Las autoridades borbónicas lograron controlar a los nuevos oradores, pero no pudieron frenar la circulación de proclamas y discursos escritos.

\section{ESCRITORES Y EDITORES POR LA CONQUISTA DE LA OPINIÓN ${ }^{34}$}

Tras el estallido de la Revolución Francesa en 1789 las autoridades borbónicas trataron de evitar el contagio imponiendo restricciones a la circulación

${ }^{30}$ Reflexiones sobre la famosa arenga, pronunciada en Lima por un individuo de la universidad de San Marcos, con ocasion del recibimiento que hizo dicha universidad a su virrey, el excmo sr. Don Agustin de Jauregui y Aldecoa, el dia 27 de agosto de 1781 por Juan Baltasar Maciel, CDIP, I, 3, 1974: 107.

31 Examen del texto del «Elogio» en la oficina de la Secretaria de Indias, por orden de José de Gálvez, aprox. 17 de julio de 1785, CDIP, I, 3, 1974: 252-53.

32 Decreto del virrey Croix sobre libros prohibidos y expediente de Baquíjano, Lima, 20 de julio de 1786. CDIP, I, 3, 1974: 263-64. Véase también Bando del Virrey Croix disponiendo la censura de impresos. Lima, 11 de agosto de 1786, CDIP, I, 3, 1974: 263-64.

${ }_{33}$ Memorial de Baquíjano al virrey expresando su arrepentimiento por el Elogio, Lima, julio de 1786. CDIP, I, 3, 1974: 259-61. Véase también Burkholder, 1980: 66.

${ }^{34}$ De acuerdo a los diccionarios de la Real Academia de la Lengua de 1737, 1780, 1791 y 1803 «escritor» y «editor» son los términos utilizados en el período estudiado que más se 
de discursos y panfletos considerados subversivos. En Hispanoamérica, una de las mayores dificultades que enfrentaron las autoridades locales al tratar de cumplir con estas políticas fue su subordinación a las decisiones de la Corte en Madrid. Estas cambiaban con rapidez y las notificaciones tardaban meses en llegar. Así, por ejemplo, entre 1789 y 1792, el ministro conde de Floridablanca buscó frenar la información venida de Francia. Pero sus medidas se relajaron durante el gobierno del francófilo Conde de Aranda (1792) y los primeros años de Manuel Godoy en el poder (1792-94) cuando España se vio inundada de panfletos y periódicos, al tiempo que recibió a numerosos emigrados franceses. Y si bien el estallido de la guerra entre la Francia revolucionaria y España en 1793 llevó a mayores controles y frenó en algo la penetración de propaganda, ésta se reanudó en 1795 tras el tratado de paz entre las dos naciones ${ }^{35}$. En consecuencia, libros y panfletos franceses así como textos ingleses y norteamericanos circularon con facilidad en España y América ${ }^{36}$.

Una manera efectiva de esquivar la censura y difundir textos prohibidos era el envío de copias manuscritas que algunos solían adjuntar con sus cartas a familiares y amigos en España o América ${ }^{37}$. Es así como en 1796 circuló en Lima una traducción hecha en el Perú del Discurso sobre las Artes y Ciencias de Jean Jacques Rousseau. El texto es particularmente interesante pues el traductor aprovechó para anotar al pie de página sus opiniones sobre la manera en que las ideas del filósofo francés podían adaptarse al virreinato peruano. Siguiendo a Rousseau, el traductor pretendía demostrar su capacidad para ejercer la crítica. En las notas condenaba la pompa y desigualdad social, así como el exceso de literatos y soldados que proliferaban en el Perú. En su opinión, la sociedad necesitaba: «labradores, pastores, texedores... porque si las ciencias corrompen las costumbres lo mismo hace la guerra; pudiendose asegurar por donde haya tropas regladas, no habrá sino despotismo y corrupcion ${ }^{38}$.

ajustan a las actividades desempeñadas por los hombres de letras en el campo de la opinión pública. Ver buscon.rae.es

${ }^{35}$ Herr, 1958, caps. 8-10.

36 Ibidem: 373. Ver también Spell, 1938, primera parte.

37 Ver por ejemplo: Retractacion que a la hora de la muerte hizo de su probabilismo el Padre Fr. Joseph Cliquet Author de la obra intitulada Flor del Moral, AGN, Colección Moreyra Misc., D. 1, 103-198 y La Nacion Hebrea al General Bonaparte, 1794-1795. AGN, Colección Moreyra, D. 1, 103-354. Sobre la circulación de textos subversivos en Perú ver Rosas, 2006, cap. 2.

${ }^{38}$ Discurso que merecio el premio propuesto por la Academia de Dijon el año de 1750 sobre esta question ¿Si el restablecimiento de las Ciencias, y de las Artes ha contribuido a purificar las costumbres? Por un Ciudadano de Ginebra. Traducido en el Peru año de 1796, Yale University, Andean Collection, caja 32, carpeta 187. 
Escritos como el anterior no sólo llegaron a manos de la élite. En algunas ocasiones las autoridades descubrieron a gente del común leyendo textos prohibidos. Las investigaciones que ordenaron al respecto nos han legado una valiosa documentación. En 1794, por ejemplo, las autoridades de Lima se sobresaltaron cuando supieron que unos vecinos franceses y sus amigos se habían reunido en la fonda del Caballo Blanco para dar vivas por la muerte del rey Luis XVI de Francia. Los sospechosos desempeñaban ocupaciones plebeyas como las de hojalatero, barbero, pintor, escultor y copista. De acuerdo a las investigaciones, uno de sus mayores crímenes había sido el circular entre ellos copias del famoso discurso de Mirabeau a la Asamblea Nacional. Igualmente grave fue el hallazgo de un retrato de Voltaire entre los manuscritos y libros sediciosos guardados en el pequeño cuarto de Joaquín Alzamora, un mulato de Panamá, «con destino escriviente» y profesor de francés, que había servido en su juventud de secretario y mayordomo del famoso oficial borbónico Antonio de Ulloa ${ }^{39}$.

Poco podían hacer las autoridades reales para contener la circulación de información, cuando ellas mismas habían promovido la publicación de gacetas y periódicos en el imperio con el fin de difundir noticias y conocimientos prácticos que ayudaran a la reforma ${ }^{40}$. Así, en los primeros años de la década de 1790 se editaron tres periódicos en Lima: El Diario de Lima (1790-1793), El Mercurio Peruano (1791-1794) y El Semanario Crítico (1791), al tiempo que llegaban con regularidad los periódicos peninsulares. Lima solía recibir El Espiritu de los Mejores Diarios (1787-1791) y El Diario de Madrid (17881825), impresos con permiso real, que difundían noticias de Francia. Pero también llegaba el controversial El Censor (1781-1787), que publicaba artículos críticos sobre la sociedad española, los privilegios y la falta de educación ${ }^{41}$.

La prensa limeña de finales del siglo XVIII ha sido estudiada de manera extensa ${ }^{42}$. Lo que interesa aquí es analizar la forma en que los editores concibieron su función como escritores y líderes de opinión. Por entonces la «opinión pública» surgía como una realidad nueva con fuerza propia, que algunos hombres de letras aspiraban ingenuamente a controlar ${ }^{43}$.

39 Causa seguida en Lima contra varios franceses sobre juntas y palabras sediciosas. Los procesados son: Joaquín Alzamora, Carlos Fournier, Monsieur Clermont, Clemente Sabino, Pedro Blanc, Pedro Viana. 1794-1795, Archivo Histórico Nacional, Madrid (AHN), Consejos, leg. 21290, n. ${ }^{\circ}$ 211. Sobre este caso véase Rosas, 2005: 139-166 y 2006.

40 Herr, 1958: 183-200.

${ }^{41}$ Sobre la prensa española ver también Seoane, 1977.

42 Sobre el desarrollo de la prensa en el virreinato del Perú ver: Martínez Riaza, 1985. Clement, 1997. Chassin, 1998. Peralta, 2006. Velázquez (ed.), 2009.

${ }^{43}$ Para un análisis del surgimiento de la opinión pública en las últimas décadas del virreinato ver Chassin, 1998. 
Tal fue el caso de Jaime Bausate y Mesa, el editor del Diario de Lima, quien en la introducción a su periódico anunciaba que su rol sería el de un intermediario en la cadena del conocimiento, mediando entre los filósofos y los salvajes ${ }^{44}$. Con ese fin, su diario siguió un estilo claro y didáctico en la forma de diálogos. Bausate era un típico reformista ilustrado. Gracias a los estudios de Jean Pierre Clement sabemos que este extremeño tenía tan sólo veintiséis años cuando inició su empresa periodística en Lima, aunque ya antes se había desempeñado como profesor en Madrid en el Real Seminario de Nobles, la escuela más importante del imperio español, y había colaborado con el prestigioso Diario Curioso, Erudito y Comercial ${ }^{45}$. Ufanado por su experiencia en la Corte, el editor del Diario de Lima no vaciló en enaltecer su función como difusor de Las Luces en el virreinato del Perú. La sección del Diario dedicada a las cartas de los lectores, que probablemente fueron todas escritas por él, le brindó un espacio propicio. Por ejemplo, en uno de sus primeros números, Bausate incluyó la comunicación de un tambero (administrador de fonda o posada) de las afueras de Lima. A imitación de su maestro Bausate en su rol de intermediario, el tambero sostenía desempeñarse como maestro a nivel local. En su carta relataba su excitación cuando los «negros palanganas» de Lima le traían el Diario y cómo él, en recompensa, les regalaba abundantes camarones y licor. Pero un día, ante la burla de uno de los caporales de las haciendas vecinas, quien le preguntara si esos papeles eran acaso algún título que el rey le enviaba, el tambero respondió que ésos eran «los Diarios, que con privilegio de este Real Superior Gobierno, daba á luz Don Jaime Bausate y Mesa» ${ }^{46}$.

Los diálogos del Diario de Lima revelan también las críticas que Bausate tuvo que enfrentar tras presentarse como difusor del conocimiento en el Perú. Sus mayores adversarios fueron los editores del Mercurio Peruano,

44 «Interesa mucho á todo Ciudadano considerar los progresos de las Ciencias, y Artes; ver por que medios los hombres se han aproximado á la verdad, ó han caido en el error; y finalmente como han seguido, interrumpiendo y vuelto á tomar el ilo de los conocimientos.

Desde los salvajes, á quienes las necesidades obligaron á formar las primeras ideas, hasta el filosofo que revela los ultimos descubrimientos, hay una cadena de pensamientos, eslabonada de relaciones. No quiero en este corto volumen, fixar la Pluma en referir la utilidad, que resulta a la Pro comun el conocimiento de los Papeles periodicos; pues bastará solo la prueba, que nos dan los que diariamente corren en las principales Cortes de Europa». Analisis del Diario Curioso, Erudito, Economico, y Comercial, que con privilegio de este Real y Superior Govierno da a Luz Don Jayme Bausate y Mesa. En la Ymprenta de Niños Espocitos de Lima, AGN, Colección Moreyra, Miscelánea, copia manuscrita. Este fue el texto introductorio al primer número del Diario de Lima.

${ }^{45}$ Clément, 2006. Véase también Representación que hace D. Jayme Bausate y Mesa, 1791.

${ }^{46}$ Diario de Lima (en adelante $D L$ ), 13 de octubre de 1790. 
quienes pertenecían al círculo aristocrático liderado por José Baquíjano y Carrillo. El prestigio de representar a la élite limeña, además de contar con el apoyo directo del virrey Francisco Gil de Taboada (1790-1796), hizo que los «mercuristas» se proclamaran como autoridades nuevas e indiscutibles ${ }^{47}$. Aunque muy pronto tuvieron que enfrentar el desafío de José Antonio de Olavarrieta ${ }^{48}$. Este fraile franciscano de origen vasco llegó a Lima en 1791 a los treinta años de edad tras servir como capellán en un barco de la Compañía de Filipinas. Al poco tiempo inició su empresa editorial. En el mejor estilo ilustrado, tituló su periódico: Semanario crítico, ó reflexiones críticas sobre la educación, costumbres públicas, poesía teatral, y otras materias. Al igual que Bausate, Olavarrieta concebía su diario como un instrumento para educar y reformar la sociedad. En su introducción enfatizaba que su diario no estaba dirigido a los «sabios Maestros y eminentes Doctores» sino al vulgo ${ }^{49}$. Por ello, la publicación consistía en un folleto escrito enteramente por él en un estilo breve y simple. Sus temas principales eran la reforma de la educación y las tradiciones. Con este fin, Olavarrieta se dedicó a discutir el rol de las amas de leche en la crianza de los hijos y copió casi literalmente, aunque sin citarlo, párrafos enteros del Emile de Rousseau. Al mismo tiempo se entregó a enseñar el uso de la razón y la crítica. Olavarrieta consideraba que cualquier hombre sensato tenía la capacidad de comprender y razonar. Sólo necesitaba educarse. Y él brindaría a sus lectores los instrumentos necesarios. Como buen ilustrado, Olavarrieta se propuso propagar el uso de la razón a través de la crítica teatral. Con este fin, se dedicó a enseñar en sus cuartillas las reglas básicas del arte dramático pues creía que la crítica de espectáculos entrenaría a los lectores en el ejercicio del pensamiento crítico $^{50}$. Enseguida los «mercuristas» respondieron con críticas pues consideraban que esas ideas podían aplicarse a Francia, Inglaterra y España pero no eran convenientes para el Perú ${ }^{51}$. El franciscano vasco, sin embargo, prometía cumplir el deber cívico de propagar Las Luces a todos y respondió a los «mercuristas», criticándolos por pedantes y exclusivistas ${ }^{52}$. Estos juicios expresados por escrito al público general provocaron la indignación de los «mercuristas», quienes lo acusaron

${ }^{47}$ Sobre el patrocinio directo del virrey en esta empresa, ver Progresos y estado actual de la sociedad de Amantes del Pais por el Señor Oidor, Presidente de ella, Don Ambrosio Cerdán y Pontero, s/f, Yale University, Andean Collection, caja 33, carpeta 222. Véase también Estenssoro, 1992a y 1992b. Riva-Agüero, 1971: 17-109.

48 Sobre la trayectoria de Olavarrieta, Gil Novales, 1979. Sánchez Hita, 2009.

49 Semanario Crítico (en adelante SC), n. ${ }^{\circ}$ 1, s/f, 1791. Ver también Sánchez Hita, 2009.

${ }^{5} \mathrm{SC}, \mathrm{n}^{\circ}{ }^{2}$, s/f. Ver Estenssoro, $1992 \mathrm{~b}$.

${ }^{51}$ Mercurio Peruano (en adelante MP), 9 de junio de 1791.

${ }^{52} \mathrm{SC}, \mathrm{n}^{\mathrm{o}}{ }^{3}$, s/f. 
de intentar provocar faccionalismos y odios entre americanos y europeos ${ }^{53}$. Olavarrieta rechazó tal condena y se proclamó defensor de Lima, en especial de las mujeres y los negros, en contra de los charlatanes ${ }^{54}$. Por su parte, Bausate también criticaba a los «mercuristas» por exclusivistas y burlonamente los amenazó con fundar una sociedad similar a su Sociedad de Amantes del País pero compuesta por gente con rasgos horribles.

Es así como gran parte de la energía de los tres primeros periódicos limeños estuvo dedicada a rivalizar entre sí y a reclamar la autoridad y primacía de su opinión. Los choques se acentuaron con el tiempo y terminaron debilitándolos. El Semanario dejó de existir en 1791, el Diario de Lima en 1793, y el Mercurio publicó su propia «Oración Fúnebre» en agosto de 1794. En ésta los «mercuristas» se quejaban de la mala fortuna que habían tenido como hombres de letras. En un inicio todo habían sido alabanzas, pero luego todo se volvió crítica. Cómo era posible - escribían - que:

Amor patriótico, ilustración pública, fomento á la Literatura, se hicieron unas palabras de moda, que no faltaban ya hasta en la boca de las mugeres, y de los mulatos Palanganas. Se hubiera tenido por un Drope el pulpero que no hubiese deseado ver su nombre escrito con letras de molde en la lista de señores Suscriptores.

El obituario concluía así: «infeliz Mercurio mío! Tu que naciste para gloria y ornato del Perú... Cómo, dime, viniste á ser mas Chabacano que el Dios, mas frívolo y charlatán que el Semanario Crítico? $\gg^{55}$ Los «mercuristas» sostenían que la necesidad de popularizar sus escritos había causado la ruina de su empresa. Se equivocaban. El Mercurio tuvo problemas para imponer sus temas desde un inicio, sobre todo en sus últimos años cuando las noticias clandestinas acerca de la revolución y el terror en Francia, así como los libelos contra Godoy y la reina resultaban mucho más interesantes que los partes oficiales de guerra o los largos y tediosos artículos acerca del comercio libre y la coca. Los escritos políticos - la crítica de autoridades y formas de gobierno- ganaban cada vez mayores adeptos.

\section{LA IRRUPCIÓN DE LOS NUEVOS ABOGADOS}

El tardío siglo XVIII presenció también el surgimiento de los nuevos abogados, doctores en leyes que se erigían con el poder de criticar autorida-

${ }^{53} \mathrm{SC}, \mathrm{n}^{\mathrm{o}}$ 5, s/f.

${ }^{54}$ Idem.

55 «Oración fúnebre histórico-panegírica que en las exequias del Mercurio Peruano, pronunció Su padre de Agua...»MP, 21 de agosto de 1794; 24 de agosto de 1794. 
des y proponer formas nuevas de gobierno. Desde el temprano siglo XVIII los Borbones llevaron a los ministerios y consejerías a abogados talentosos educados profesionalmente, muchos de los cuales pertenecían a la nobleza de segundo orden o a la élite provinciana. Tal fue el caso de José Moñino, Pedro Rodríguez de Campomanes y Gaspar Melchor de Jovellanos. Entre otras tareas, la Corona les encomendó el elaborar una legislación nueva que reformara el modelo corporativo de sociedad que había primado durante la dinastía Habsburgo. Para llevar a cabo la ciclópea tarea, este grupo de abogados reales consideró necesario formar cuadros que, como ellos, se entrenaran en escuelas nuevas y especializadas. Ello suponía reformar y controlar las universidades. Este es un tema vasto y complejo, cuyo cabal estudio demanda un espacio mayor. Aquí me centraré en la introducción de los cursos de derecho natural y de gentes, un aspecto central del plan de reformas educativas que además jugó un rol clave en la transformación de los abogados en actores políticos ${ }^{56}$. Con la difusión de estos cursos en academias especializadas en derecho civil, la Corona creó a los abogados modernos. Sus conocimientos renovados, así como su aceptada capacidad para ejercer la crítica, los convirtió en autoridades nuevas.

En su afán por promover estudios prácticos que sirvieran a los intereses de la Corona, en 1771 Carlos III impuso como obligatorios los cursos de derecho natural y de gentes para todos los graduados que postularan a una licencia en Madrid. Las academias y universidades de España y América empezaron a dictarlos al poco tiempo ${ }^{57}$. Así, la monarquía española se puso a la vanguardia europea en este campo, pues si bien estos cursos existían en los países germano-protestantes, Francia careció de ellos durante todo el siglo XVIII ${ }^{58}$. Pero pronto los sectores tradicionales de la Universidad y la Iglesia se opusieron tajantemente tanto en España como en el Perú ${ }^{59}$. ¿Qué era lo que les molestaba de estos cursos? En primer lugar la crítica al método escolástico, pues consideraban los cursos una directa amenaza al rol predominante del derecho canónico y romano, dos bastiones de la universidad. En segundo lugar, temían que estos cursos demandaran la incorporación de catedráticos nuevos que pudieran escapar al control de los viejos profesores.

${ }^{56}$ Sobre el papel de estos cursos en el surgimiento de una tradición liberal constitucional en España véase Herr, 1958: 182-183. Sobre su rol en los movimientos de independencia véase el estudio pionero de Chiaramonte, 2004. Sobre la instauración de estos cursos en la península véase Peset y Peset, 1983. Peset 1974: caps. 12-14; 1968.

57 Herr, 1958: 173.

58 Chiaramonte, 2004: 108-109.

59 Herr, 1958: cap. 7. Peset y Peset, 1983: caps. XII-XIV. Para el Perú véase Barreda Laos, 1937: 304-308. García Calderón, 1862: 66-74. 
Pero sobre todo las autoridades tradicionales se oponían al contenido de los cursos, porque consideraban los textos de derecho natural y de gentes como subversivos y herejes. La mayoría de los autores compilados, como Grotius, Heineccius, Puffendorf y Hobbes, eran protestantes y constituían, por tanto, una amenaza. Más aún, estos textos citaban a autores prohibidos como Montesquieu. Su preocupación se acrecentaba ante la popularidad que estas materias suscitaban entre los jóvenes. Como refiere José Cadalso en Eruditos a la violeta, una sátira escrita hacia 1771 , las enseñanzas del derecho natural $\mathrm{y}$ de gentes andaban en boca de todos, en especial de los educados "publijuris-peritos $\rangle^{60}$. Este tipo de conversaciones sobre las maneras en las que se organizan las sociedades resultaba sumamente preocupante para los defensores del viejo orden, pues suponían que la política podía ahora ser debatida en público y por todo aquel que estudiara estos cursos. En palabras de Cadalso:

La lección de este día es muy trivial. No se trata más que de lo que se debe el hombre a sí mismo y a los demás hombres, lo que un Estado tiene que cuidar dentro de sí mismo y respecto de los otros estados. Esto, ya veis, en sustancia es una grandísima friolera. Antiguamente no hablaban de esta facultad sino aquellos a quienes competía, como príncipes, embajadores y generales. Pero ¡tiempos bárbaros serían aquellos en que no hablase cada uno más de lo que le toca! ¡Qué diferentes son los nuestros! En ellos no hay cadete, estudiante de primer año ni mancebo de mercader que no hable de Menchaca, Ayala, Grocio, Wolfio, Pufendorf, Vatel, Burlamachy, etc. ${ }^{61}$.

Las autoridades de la Universidad y la Iglesia tenían razón de preocuparse pues muchas de las ideas propagadas en los manuales y cursos eran en efecto radicales y hasta subversivas para el mundo hispánico. Por ejemplo, en su Historia del derecho natural y de gentes, publicada con auspicio real en 1776, el catedrático del Real Seminario de Nobles de Madrid, Joaquín Marín, explicaba que existía una política buena y una mala. Siguiendo las enseñanzas del padre José Benito Jerónimo Feijoó, Marín apuntaba:

La advertencia que me parece mas importante en esta materia es, dar á conocer con tiempo á un Principe mozo, ó á cualquiera otro niño, la diferencia de la verdadera y de la falsa Política. Que tome horror á lo que tiene solo por fin hacer poderoso al Principe, ó al Cuerpo, que gobierna, á costa de todo lo restante del pueblo. A que no ponga la virtud del Soberano en mantener, y aumentar su poder, dexando á los particulares la justicia, la fidelidad, y la humanidad ${ }^{62}$.

${ }^{60}$ Cadalso, 1967 [1772].

${ }^{61}$ Ibidem: 89.

${ }^{62}$ Marín, 1776: 9. Para una distinción similar entre política «verdadera» y «falsa», véase «La política más fina», Feijoo, 1726. 
Sin mayor reparo, Marín promovía en su historia las virtudes de «L'esprit de loix [que] ha corrido, y corre, ya vertida ya en su idioma propio con mucho aplauso por toda la Europa, en la que además de que se excitan muchas observaciones profundas sobre la esclavitud, sobre el derecho de la guerra y la conquista, y en otros varios puntos de esta materia, es muy notable su nuevo modo de pensar, por lo menos en lo que toca á la naturaleza, y forma de los Estados» ${ }^{63}$.

Entre las teorías que podían ser consideradas peligrosas, estaban las del derecho natural que proclamaba que todos los hombres en su condición natural eran iguales y por lo tanto poseían los mismos derechos y obligaciones, como el derecho a la libertad y a resistir la tiranía. No sorprende que los mayores entusiastas de estos cursos fueran precisamente los maestros de leyes jóvenes que carecían de prestigio social pero aspiraban a que su educación profesional y mérito los colocara en puestos de autoridad. Es el caso, por ejemplo, de Toribio Rodríguez de Mendoza en Lima, quien abogó tenazmente y con éxito por la introducción de estos cursos. Como profesor primero y luego como rector, Rodríguez de Mendoza formó a una generación de abogados en el Convictorio de San Carlos, quienes décadas más tarde se convertirían en los líderes liberales del Perú republicano, siendo él uno de los protagonistas del primer Congreso constituyente y una de las figuras más importantes en el inicial diseño constitucional del Perú ${ }^{64}$.

Pese al entusiasmo por los cursos de derecho natural y de gentes, el aumento de las protestas en su contra, las guerras revolucionarias en Francia y el temor a una insurrección en España llevaron a su prohibición en $1794^{65}$. Esta sanción tuvo corta vida, pues las reformas de Godoy los restauraron en 1802 cuando se decretó la unificación de todas las facultades de leyes en el imperio $^{66}$. Posteriormente, durante las Cortes de Cádiz y el apogeo del liberalismo los cursos cobraron un nuevo auge ${ }^{67}$.

Por otro lado, las reformas borbónicas no sólo contribuyeron a aumentar la autoridad de los abogados sino también su número. Ante la imposibilidad de llevar a cabo una reforma universitaria drástica, Carlos III, por consejo de Floridablanca, apoyó la creación de academias particulares de derecho y de seminarios conciliares, como el Convictorio de San Carlos en Lima, donde se pudieran dictar libremente cursos de interés para la Corona ${ }^{68}$. Con el fin de

\footnotetext{
${ }^{63}$ Marin, 1776: 41-42.

${ }_{64}$ Romero, 1973, caps. 12 y 13. Lanning, 1971.

${ }^{65}$ Herr, 1958: 371.

${ }_{66}$ Peset y Peset, 1983: 222-224 y 262-268. Véase también Real Cedula de S.M. 1807.

67 Peset, 1968: 248-294.

${ }^{68}$ Espinoza, 1999. Cubas, 2001.
} 
sortear los controles de la universidad en el otorgamiento de títulos, el monarca instauró en 1770 a los abogados de Audiencia, cuyos títulos eran conferidos directamente por esta institución, lo cual contribuyó también a la multiplicación del número de abogados ${ }^{69}$. En las guías políticas o calendarios al uso del siglo XVIII, estos nuevos profesionales aparecen listados con sus nombres y direcciones, en una demostración de su nuevo status social y político ${ }^{70}$.

Siguiendo con esta línea, la Corona ordenó en 1804 la creación de colegios de abogados en la Península y América. El virrey Abascal estableció un colegio de este tipo en Lima en 1808 (Estatutos para el gobierno 1808) ${ }^{71}$, cuya política de admisión relativamente inclusiva es sorprendente, pues se aceptaba tanto a hijos legítimos como naturales, siempre y cuando no tuvieran sangre de moros ni de judíos. Los estatutos no estipulaban restricciones para las castas, lo cual contribuiría también al aumento del número de abogados ${ }^{72}$. Para ese entonces, muchas ciudades de la América española demandaban el establecimiento de universidades que pudieran formar a sus propios abogados. Tal fue el caso de Arequipa que por iniciativa del obispo Chávez de la Rosa y tras largas negociaciones, obtuvo el permiso legal para graduar estudiantes en su seminario, siempre y cuando suprimiera los controvertidos cursos de derecho natural y de gentes ${ }^{73}$.

La instalación de una Audiencia en el Cuzco en 1787 contribuyó también a la inflación en el número de abogados, escribanos y picapleitos en la ciudad ${ }^{74}$. A esta Audiencia le correspondía graduar estudiantes cuzqueños de la Universidad San Antonio Abad y del Colegio de San Bernardo, pero también tenía jurisdicción para tomar exámenes de grado a los estudiantes de la región. Por esta razón, el Cuzco recibía estudiantes de Guamanga, Arequipa, Charcas y del norte de Río de la Plata ${ }^{75}$. Para ese entonces, sin embargo, la ciudad se había convertido también en un centro militar importante y no tardaron en surgir los

${ }^{69}$ Fuente, 1889, vol. 4: 173-174, 255.

${ }^{70}$ Guia política, 1797. Abogados del ilustre colegio de la M.N.Y.L. Ciudad de Cadiz, que actualmente residen en ella. Archivo General de Indias (en adelante AGI), Arribadas 315. Guía de litigantes, 1803. Kalendario manual, 1803.

${ }^{71}$ Para entender la política cultural de Abascal y las relaciones entre el poder central y las élites locales es fundamental la investigación de Peralta, 2002.

72 Estatutos para el gobierno, 1808, artículo 4.

73 García Calderón, 1862: 73-74.

74 Entre los años 1802 y 1807, se recibieron 61 estudiantes en derecho por la Universidad San Antonio Abad del Cuzco, 40 en Teología, 6 en Filosofía y 3 en Medicina. Libro donde se apuntan las partidas de los grados que se confieren en esta Real Pontifica Universidad de N.P.S. Abad. Archivo Regional del Cuzco (en adelante ARC), Documentos de la dirección, leg. 50. Cuzco, 1802-1807.

${ }^{75}$ ARC, Real Audiencia, Gobierno, legajos 158-159. 
conflictos entre abogados y soldados milicianos. Era común que los militares desobedecieran las órdenes de la Audiencia o de los jueces civiles y que las disputas provocaran la frustración de los abogados al ver su autoridad desafiada. Así, en 1803 el recién nombrado teniente asesor interino de la audiencia del Cuzco, Manuel de Ubalde, personaje principal de la próxima sección, intentó en vano encarcelar a unos soldados por sedición. Estos, protegidos por el fuero militar, se libraron de toda pena, provocando la indignación de Ubalde quien en un informe escrito con gran elocuencia y exaltación protestaba contra el atropello de su jurisdicción y se esforzaba por dejar en claro su autoridad:

Si como es imposible su calificación por manifiestamente calumniosos tuvieran un solo atomo de verdad harian caer toda la iliada de penas que corresponde a semejantes excesos sobre los Jueces de esta Ciudad. Ellos [los jueces] son el blanco contra quien han encaminado sus tiros los Artilleros sin advertir el respeto que se merecen como verdaderos sacerdotes de la justicia, Padres de la Patria, personas sagradas y verdaderos representantes del Soberano ${ }^{76}$.

Es así como la decisión de promover los cursos de derecho natural y de gentes con el fin de profesionalizar a los abogados auspició el debate político público ${ }^{77}$. La meta de estos abogados ya no era el aplicar una legislación antigua a situaciones particulares, sino el pensar críticamente sobre formas de gobierno y el proponer leyes. Pronto descubrieron que también podían planear conspiraciones e idear nuevos órdenes sociales que los llevaran al poder.

\section{LOS CONSPIRADORES}

Uno de los roles menos esperados en la transformación de hombres de letras en nuevos actores políticos fue el de conspiradores. La vida política en España y en el mundo atlántico cambió tras las revoluciones francesa y haitiana ${ }^{78}$. Y si bien los intentos de urdir conspiraciones y llevarlas a cabo no tuvieron las mismas repercusiones que en aquellos casos, estos alarmaron y crearon tensiones. Las indagaciones y los procesos judiciales que suscitaron, nos han legado una valiosa documentación acerca de las metas y ambiciones de los líderes.

\footnotetext{
${ }^{76}$ Expediente promovido por los Yndividuos del Real Tren de Artilleria de esta Plaza sobre que se les mantenga en la posesion del fuero que gosan y no se les biblipendee por los Jueses ordinarios, ARC, Real Audiencia, Administración, legajo 150, 1802-1805.

${ }_{77}$ Sobre el surgimiento de una oposición política en España a fines del siglo XVIII véase Herr, 1958, cap. 11. También Aymes, 2005.

${ }^{78}$ Para una nueva historiografía política e intelectual sobre las estas revoluciones, ver Dubois, 2004.
} 
Entre los intentos subversivos más sonados de la metrópoli estuvo la llamada conspiración de Picornell, encabezada por profesores y abogados. Fue descubierta en 1794, cuando los plateros de Madrid alertaron a Manuel Godoy acerca de una conjura inminente que iba a estallar durante la fiesta de San Blas. Como ha estudiado Antonio Elorza, el líder era Juan Mariano Picornell, un ilustrado mallorquín, que creó una escuela privada en Madrid y tradujo en 1797 la versión de Danton de la Declaración de los Derechos del Hombre y Ciudadano. Su círculo de conspiradores contaba con un profesor de humanidades, un candidato a la cátedra de matemáticas de la Universidad de Salamanca, un abogado y un profesor de francés. Todos pertenecían al grupo marginal o secundario de la universidad que defendía una reforma educativa radical que acabara con las autoridades tradicionales. Su plan era organizar un levantamiento masivo contra Godoy durante la invasión francesa de Irún y lograr el apoyo del pueblo de Madrid. De acuerdo a sus proyectos, una vez tomado el poder, los profesores impondrían una monarquía constitucional. El plan fue delatado y Godoy sentenció a los líderes a cumplir sus penas en América ${ }^{79}$.

Como lo revela el proceso judicial que se abrió en su contra, los conspiradores consideraban clave conjugar sus acciones con discursos pues para estos hombres de letras, el poder de la palabra era enorme. Por ello, Picornell y sus allegados circularon dos panfletos titulados Manifiesto e Instrucción. Según las autoridades, el primer texto mostraba:

...con las expresiones más sediciosas los motivos que ellos suponían asistir al Pueblo para hacer un trastorno general en el Gobierno y Orden público, reintegrándole en los derechos que llaman imprescriptibles y en virtud de los cuales le suponen autorizado para mudar, reformar, alterar y establecer la constitución el reino en la forma que más bien le pareciese ${ }^{80}$.

El Manifiesto era una suerte de declaración de los derechos del hombre en España, un llamado a «salvar a la Patria de la entera ruina que la amenaza», una crítica a los vicios del gobierno y una explicación de las funciones y organización que tendría la Junta Suprema que ellos implantarían. Era, además, una instrucción de comportamiento para todos los españoles durante y después de esta gran transformación. La Instrucción, como las autoridades advertían, era un manual de organización revolucionaria en el que, paso a paso, se estipulaban las acciones que debía seguir el pueblo el día señalado ${ }^{81}$.

Por su parte, el Virreinato del Perú no estuvo inmune a intentos sediciosos. Hacia el cambio de siglo esta región del imperio español experimentaba

\footnotetext{
79 Elorza, 1971: 11-12. Herr, 1958: 325. Sobre este tema ver también López, 1997.

${ }^{80}$ Elorza, ibidem: 79.

81 Ibidem: 87-95.
} 
cambios críticos con reformas educativas radicales y con los inicios de una expansión militar. Así, en 1805 las autoridades del Cuzco develaron una conspiración, cuyos líderes aspiraban a crear un nuevo imperio. La historiografía sobre el tema ha considerado este suceso como un caso raro pues no guarda similitudes ni con las rebeliones contra el mal gobierno del siglo XVIII, ni con los movimientos autonomistas del XIX. En su mayoría, los historiadores han tratado de explicar la función de las evocaciones al inca en la conspiración, así como la participación indígena y el rol que jugó la ciudad del $\mathrm{Cuzco}^{82}$. Si bien estas aproximaciones han iluminado nuestro conocimiento sobre las tensiones sociales y el imaginario popular, no se ha prestado suficiente atención o no se han tomado suficientemente en serio las motivaciones de los líderes. Pero si analizamos sus expectativas personales y metas políticas, por más absurdas que parezcan, podemos encontrar un nuevo tipo de insurrección que tenía mucho más en común con las conspiraciones metropolitanas al estilo de Picornell y con la revolución francesa liderada por abogados convencidos de la necesidad de una regeneración moral de la vida política ${ }^{83}$.

La rebelión de 1805 estuvo encabezada por el mineralogista Gabriel de Aguilar, nacido en Huánuco, y el abogado Manuel Ubalde nacido en Arequi$\mathrm{pa}^{84}$. El proceso que se llevó contra él nos revela sus intenciones y frustraciones.

Tanto Aguilar como Ubalde pertenecían a los sectores medios profesionales, entusiasmados con las oportunidades creadas por las reformas y energizados por la nueva literatura y las noticias de grandes cambios en Europa. Ambos eran jóvenes y vivían afanados por labrarse un lugar prominente en los aún rígidos órdenes tradicionales del virreinato peruano. Al parecer y de acuerdo a sus diferentes declaraciones relatando sus viajes y empresas, Aguilar contaba con recursos económicos. Ese no era el caso de Ubalde quien, como les ocurría a muchos hombres de letras, vivía en una situación precaria y casi marginal. De acuerdo a su confesión, tras graduarse como abogado en el Cuzco logró encontrar un puesto bien remunerado como abogado de la Audiencia de Lima en donde vivía en «estado feliz» ${ }^{85}$. Es entonces cuando conoció a

${ }^{82}$ Para un estudio brillante acerca de los sueños de Gabriel Aguilar en la rebelión ver Flores Galindo, 1987: 175-242. Sobre la participación indígena en la conspiración y el rol político del Cuzco véase Fisher, 1982: 45-59 y Walker, 1999: 86-88.

${ }^{83}$ Ver al respecto, Friedland, 2002.

${ }^{84}$ Los apoyaban otros abogados, el cacique Diego Cusiguamán, un teniente coronel y dos sacerdotes de los conventos de San Francisco y la Merced. Ver el informe de 1805, firmado por el presidente de la audiencia y regente interino del Cuzco dirigido a las autoridades correspondientes en España, AGI, Cuzco 29.

${ }^{85}$ Primera declaración de Ubalde. Ponce Sanginés, 1975: 42 
Aguilar, quien acudió a su estudio solicitándole que lo ayudara en un pleito sobre una mina. El abogado quedó muy impresionado con la personalidad y las historias del mineralogista. Pasado algún tiempo de no tener noticias de este «personaje extraordinario», Ubalde recibió una carta suya dándole cuenta de haber caído preso y entonces decidió ayudarlo.

Al poco tiempo, Ubalde recibió la solicitud del virrey de trasladarse al Cuzco para servir como teniente asesor interino de la nueva Audiencia. Esta decisión le causó una gran decepción pues el Cuzco era entonces una ciudad deprimida y la remuneración que le esperaba era poca. Pese a su desagrado, aceptó $^{86}$. Ubalde declaró sentirse aislado y empobrecido en su nuevo puesto. Su verdadera ambición era convertirse en juez de la Audiencia de Lima, seguir leyendo Raynal, Filangieri y otros escritores franceses o quizás ser nombrado ministro del rey como una de sus tías había soñado. Solo en el Cuzco, añoraba la visita de su amigo Aguilar ${ }^{87}$. Pues, como él mismo confesó:

Que puesto aquí [en el Cuzco], vuelvo a decir, empezó a tomar el pulso a su ningún ingreso y a la suma pobreza del lugar, se iba diariamente consternando mucho; mas al advertir que, destituído de saber y de dinero y tan separado de la Corte, era civilmente imposible su colocación en la propiedad; pero que todas esas melancólicas futuriciones las ofrecía al Señor Cristiano sacrificio de su voluntad. Que en medio de ellas hacía recuerdo de la riqueza mineral de estas regiones, de la falta de inteligentes y de la pericia de aquel D. Gabriel conocido en Lima, por cuyo medio le sería fácil al que declara evitar su mendicidad y aliviar la pobreza de este Pueblo; pero se le disipava esta idea lisonjera al advertir que aquel hombre estaría en el otro Mundo, es decir en la Europa o acaso metido entre los bárbaros, sin esperanza de volverlo a ver ${ }^{88}$.

Aguilar reapareció al poco tiempo y Ubalde decidió convertirse en discípulo suyo con la intención de aprender de sus historias y lecturas, pero también con la esperanza de beneficiarse con sus negocios de minas. Aguilar era un hombre de una gran imaginación. De acuerdo a su propio testimonio y al de los otros involucrados, sus ideas conspirativas le habrían sido reveladas en sueños desde su infancia ${ }^{89}$. Estas premoniciones se mezclaban con historias fantásticas acerca de sus travesías. Nada impresionó más a Ubalde y a los otros implicados, que el supuesto viaje de Aguilar a España ${ }^{90}$. Allí, según su relato, habría presentado a la Reina y a Godoy, en cuya casa se alojaría, unos memoriales sobre el peligro de invasiones inglesas a América por el Río Ma-

\footnotetext{
86 Ibidem: 42-43.

87 Sobre las lecturas de Ubalde, ibidem: 57. Sobre la visión de su tía, ibidem: 58-59.

88 Primera declaración de Ubalde, ibidem: 40-46.

89 Declaración de Aguilar, ibidem: 85-86.

90 Primera declaración de Ubalde, ibidem: 41-43.
} 
rañón. Su meta habría sido recibir como premio la gobernación de una región fronteriza de indios. Pero tras su escaso éxito en esta empresa y «resentido de eso y de la corrupción moral que observó en el Palacio... y generalmente de toda la corte», decidió marchar a Cádiz en busca del cónsul inglés, a quien presentaría los proyectos $^{91}$. En el supuesto viaje hacia España, y a su paso por el Río de la Plata, según la extensa declaración de Ubalde, las gentes de aquella región le habrían ofrecido «deferencias y positivas invitaciones a que se hiciese Caudillo de una mutación política» ${ }^{92}$.

Un día, en una de sus largas conversaciones, Aguilar le consultó a su amigo y abogado Ubalde si era pecado o no el participar en «una conjuración espiritual de un Pueblo para la inauguración de un nuevo Rey o cosa semejante» ${ }^{93}$. Tratando de recordar sus lecturas y conocimientos - «las predicciones políticas que ha oído del Raynal y sabe de Filangieri», los textos de San Ambrosio, varias representaciones publicadas en el Semanario Erudito y el Juicio Imparcial de Campomanes ${ }^{94}$ — Ubalde le contestó días después que de acuerdo a las doctrinas de Santo Tomás era «lícito oponerse al Gobierno cuando éste declina en tirano o tuvo principios de usurpación» pero no cuando esa acción causase perjuicios a la comunidad. Al poco tiempo comenzaron a planear el alzamiento después del cual crearían un nuevo imperio inca. Ubalde habría tratado de persuadir a Aguilar de abandonar la idea de coronarse rey de Cuzco, recordándole que no tenía ninguna relación con la ciudad y que debía evitar un derramamiento de sangre ${ }^{95}$. Siguiendo los consejos de su abogado, con quien Aguilar parecía consultar todo, el mineralogista reconoció que no tenía legitimidad para gobernar un imperio inca y que debía buscar a otra persona para ese cargo. Acto seguido, dijo - de acuerdo a la versión de Ubalde - «que si él no fuese el Rey, sería al menos la mano auxiliar que sentase a otro en el trono» ${ }^{96}$. Entonces eligieron al regidor Valverde, quien era descendiente del último Inca e intentaron casarlo con una descendiente de otro linaje incaico para reforzar así su legitimidad ${ }^{97}$. Pronto empezaron a distribuir los cargos más

91 Segunda declaración de Ubalde, ibidem: 47-48.

92 Ibidem: 47. Aguilar mismo declaró haber viajado a España en 1795. Primera declaración de Aguilar, ibidem: 86. Declaración de Don Manuel Ampuero, ibidem: 133-138.

${ }_{93}$ Tercera declaración de Ubalde, ibidem: 51.

94 Cuarta declaración de Ubalde, ibidem: 57-58.

${ }_{95}$ Las declaraciones de Ubalde no siguen un orden cronológico exacto. Tercera y cuarta declaraciones de Ubalde, ibidem: 53 y 60.

96 Tercera declaración de Ubalde, ibidem: 52-53.

97 «...mas reflexionando este ultimo que no concurrian en Aguilar los entronques y relaciones de familia para aparentar derecho a este Ymperio, y hallando a su parecer las que juzgaba necesarias en el regidor Valverde, quien se decia Nieto de los Emperadores por su 
altos de su nuevo imperio y le ofrecieron la comandancia militar al teniente Mariano Lechuga, quien los traicionó. Tras un juicio de seis meses, Aguilar y Ubalde fueron colgados en la plaza del $\mathrm{Cuzco}^{98}$.

\section{CONCLUSIÓN}

En su afán por transformar la administración y modernizar las costumbres, la Corona borbónica promovió a oradores, escritores, editores y abogados confiriéndoles una nueva autoridad y un nuevo status. En sus manos quedaba el difundir información práctica, crear leyes y reformar el viejo orden. Como se ha visto para el Virreinato del Perú, entre los dramáticos años de 1780 y 1808 , los hombres de letras estuvieron entregados a criticar autoridades, debatir sobre formas de gobierno, escribir panfletos subversivos e incluso a planear sublevaciones. Tal fue el caso de Baquíjano y Carrillo, los editores de los primeros periódicos limeños y los condenados por conspiración, Aguilar y Ubalde. Sin premeditarlo ni preverlo la Corona promovió el surgimiento de los nuevos actores políticos y de la política moderna. Es por ello que cuando Napoleón invadió España en 1808 y desató una crisis política sin precedentes en el imperio, los hombres de letras se encontraron ya listos para ejercer su liderazgo en juntas y asambleas, así como en la prensa. Algunos encontrarían en el vacío de poder creado por la invasión francesa, una oportunidad ideal para crear nuevos órdenes sociales en los cuales dominarían. Sus ambiciones sólo fueron en aumento en las décadas siguientes.

\section{BIBLIOGRAFÍA Y FUENTES IMPRESAS}

Artiga, Joseph, Epitome de la eloquencia española. Arte de discurrir y hablar con agudeza, y elegancia en todo genero de assumptos, de orar, predicar, arguir, conversar, componer embaxadas, cartas, y recados. Con Chistes, que previenen las faltas, y Exemplos, que muestran los aciertos, Barcelona, imp. Mauro Marti, Plaza de S. Jayme, 1750.

segundo apellido de Ampuero (aunque segun tengo entendido ninguna descendencia tiene de aquellos Principes) determinaron proponerselo en la primera ocasion». Expediente relativo al juicio seguido a los conspiradores Aguilar y Ubalde, Lima, 1805, BNP, D-120. Véase también, Tercera declaración de Ubalde, Ponce Sanginés, 1975:53.

${ }_{98}$ Rebelión de 1805, AGI, Cuzco, 29. 
Aymes, Jean René, Ilustración y Revolución francesa en España, Lleida, Editorial Milenio, 2005.

Barreda Laos, Felipe, Vida intelectual del virreinato del Peru, Buenos Aires, Talleres Gráficos Argentinos, 1937.

Brewer, John, Party Ideology and Popular Politics at the Accession of George III, Cambridge and New York, Cambridge University Press, 1981.

Burkholder, Mark A., Politics of a Colonial Career. José Baquijano and the Audiencia of Lima, Albuquerque, University of New Mexico Press, 1980.

Cadalso, José, Los eruditos de la violeta. Edición, prólogo y notas por José Luis Aguirre, Madrid, Aguilar, Biblioteca de Iniciación Hispánica, 1967 [1772].

Certamen ò conclusiones matemàticas, defendidas en esta Real Universidad de S. Marcos, en presencia del Excmo. Señor Virrey, Real Audiencia, y demas Tribunales, por D. Manuel Martinez de la Ruda, ayudante de la companyia de artilleros y brigada del Callao: D. Pedro Ruiz, y D. Diego Machado, cadetes de la tropa; baxo la instruccion, y direccion del Doct. D. Cosme Bueno, Catedrático de Prima de Matematicas, y Cosmògrafo mayor de estos Reynos. Dedicadas al mismo Excmo. Sr. Manuel de Amat y Junient, caballero del Orden de S. Juan: Gentilhombre de Cámara, con entrada:... El dia 11 de Junio de 1768, Lima, Imprenta Real, Calle de Palacio, 1768.

Certamen publico de derecho natural, politica y derecho de gentes que en el Real Seminario de Nobles de esta corte han de tener los caballeros seminaristas Don Remigio Argumosa, y Don Manuel de Ibarrola ... bajo la direccion de su maestro D. Manuel Joaquin de Condado, Catedrático de Derecho Natural y de Gentes del mismo Seminario el dia (sic) Diciembre de 1788, Madrid, Imprenta de la Viuda de Ibarra, s/f.

Chasin, Joëlle, "Lima, sus élites y la opinión durante los últimos tiempos de la colonia", François-Xavier Guerra et al., Los espacios públicos en Iberoamérica. Ambigüedades y problemas, siglos XVIII-XIX, México, Fondo de Cultura Económica, 1998: 241-269.

Chiaramonte, José Carlos, Nación y Estado en Iberoamérica: el lenguaje político en tiempos de las independencias, Buenos Aires, Sudamericana, 2004.

Clément, Jean Pierre, El Mercurio Peruano, 1790-1795. Textos y estudios coloniales $y$ de la Independencia, 2 vols., Frankfurt am Main, Madrid, IberoamericanaVerwuert, 1997.

Clément, Jean Pierre, “Aproximación al Diario de Lima (1790-1793) y a Jaime Bausate y Mesa, su autor", 2006, http://argonauta.imageson.org/document82.html (consultado en abril 2013). 
Colección Documental de la independencia del Perú (CDIP), vol. 1 "Los ideólogos", 3, Lima, Comisión del Sesquicentenario de la Independencia del Perú, 1974.

Cubas, Ricardo, "Educación, élites e Independencia: el papel del Convictorio de San Carlos en la emancipación peruana", Scarlett O'Phelan (ed.), El Perú en el siglo XVIII: la era Borbónica, Lima, Pontificia Universidad Católica, Instituto Riva Agüero, 1999: 289-317.

Darnton, Robert, The Devil in the Holy Water or the Art of Slander from Louis XIV to Napoleon, Philadelphia, University of Pennsylvania Press, 2010.

Diario de Lima, Prólogo, tomo I, octubre, 1790.

Dubois, Laurent, A Colony of Citizens: Revolution \& Slave Emancipation in the French Caribbean, 1787-1804, Williamsburg, Virigina, Chapell Hill, Omohundro Institute of Early American History and Culture, 2004.

Elorza, Antonio (ed.), Pan y Toros y otros papeles sediciosos de fines del siglo XVIII, Madrid, Editorial Ayuso, 1971.

Espinoza, Grover Antonio, "La reforma de la educación superior en Lima: el caso del Real Convictorio de San Carlos", Scarlett O’Phelan (ed.), El Perú en el siglo XVIII: la era Borbónica, Lima, Pontificia Universidad Católica, Instituto Riva Agüero, 1999: 205-241.

Estatutos para el gobierno y dirección del ilustre Colegio de Abogados de la Ciudad de Lima formados con arreglo a la real cedula de su erección dada en Madrid a 31 de julio de 1804. Aprobados por esta Real Audiencia, Lima, Impresos en la Real Casa de Niños Expositos, 1808.

Estenssoro Fuchs, Juan Carlos, "Modernismo, estética, música y fiesta: élites y cambio de actitud frente a la cultura popular. Perú 1790-1850”, Enrique Urbano (ed.) Tradición y modernidad en los Andes, Cuzco, Centro Bartolomé de las Casas, 1992a: 181-195.

Estenssoro Fuchs, Juan Carlos, "La plebe ilustrada: el pueblo en las fronteras de la razón," Charles Walker (ed.), Entre la retórica y la insurgencia: las ideas y los movimientos sociales en los Andes siglo XVIII, Cuzco, Centro Bartolomé de las Casas, 1992b: 33-66.

Feijoó, José Benito Jerónimo, “La política más fina,” (1726), Teatro crítico universal, tomo 1, 1778, http://www.filosofia.org/bjf/bjft104.htm (consultado en abril 2013).

Flores Galindo, Alberto, Buscando un Inca, Lima, Editorial Horizonte, 3. a ed., 1987.

Fisher, John, "Regionalism and Rebellion in Late Colonial Peru: The Aguilar Ubalde Conspiracy of 1805", Bibliotheca Americana, vol. 1, 1982: 45-59.

Fisher, John, El Perú borbónico, 1750-1824, Lima, IEP, 2000. 
Friedland, Paul, Political Actors. Representative Bodies \& Theatricality in the Age of the French Revolution, Ithaca and London, Cornell University Press, 2002.

Fuente, Vicente de la, Historia de las universidades, colegios y demás establecimientos de enseñanza en España, Madrid, Imprenta de la Viuda é hija de Fuentenebro, vol. 4, 1889.

Fumaroli, Marc, L'age de l'éloquence: rhétorique et "res literaria”, de la renaissance au seuil de l'époque classique, Geneva, Droz, Paris, Champion, 1980.

García Calderón, Francisco, "Universidad de Arequipa, Memoria sobre el estado y los progresos de la instrucción pública en Arequipa", Anales Universitarios del Perú redactados y publicados por el D. D. José G. Paz-Soldán, Lima, Imprenta de la "Epoca" por J. E. Del Campo, vol. 2, 1862: 65-96.

Gil Novales, Alberto, “Clararrosa americanista”, Homenaje a Noël Salomón. Ilustración española e independencia de América, Barcelona, Universidad de Barcelona, 1979: 113-124.

Guerra, François-Xavier, Modernidad e independencias: ensayos sobre las revoluciones Hispánicas, Madrid, Mapfre, 1992.

Gilbert-Santamaría, Donald, Writers on the Market. Consuming Literature in Early Seventeenth-Century Spain, Lewisburg, Bucknell University Press, 2005.

Guía de litigantes y pretendientes, Madrid, Por D. Benito Cano con privilegio del Rey N.S., 1803.

Guía política, eclesiástica y militar del virreynato del Peru para el año de 1797. Compuesta de órden del Superior Gobierno por el doctor don Joseph Hipólito Unanue, catedrático de anatomía en la Real Universidad de San Marcos, Lima, Imprenta Real de los Niños Huérfanos, 1797.

Hamnett, Brian, "Process and Pattern: A Re-Examination of the Ibero-American Independent Movements, 1808-1826", Journal of Latin American Studies, 29/2 (Cambridge, 1997): 227-328.

Herr, Richard, The Eighteenth-Century Revolution in Spain, Princeton, New Jersey, Princeton University Press, 1958.

Hunt, Lynn, Inventing Human Rights: A History, New York y Londres, W. W. Norton, 2007.

Kalendario manual y guia de forasteros en Madrid para el año de 1803, Madrid, Imprenta Real, 1803.

Lanning, John Tate, Academic Culture in the Spanish Colonies, Port Washington, NY., Kennikat Press, 1971.

López, Casto Fulgencio, Juan Picornell y la conspiración de Gual y España, Caracas, Academia Nacional de la Historia, 1997. 
Marin, Joachin, Historia del derecho natural y de gentes por Don Joachin Marin, abogado de los Reales Consejos, del Ilustre Colegio, y Cathedratico de este mismo Derecho, en los Reales Estudios de esta Corte. Madrid, D. Manuel Martin, Calle de la Cruz, 1776.

Martínez Riaza, Ascensión, La prensa doctrinal en la independencia del Perú, 18111824, Madrid, Ediciones Cultura Hispánica, Instituto de Cooperación Iberoamericana, 1985.

Mercurio Peruano, 1791-1795, Lima, Biblioteca Nacional del Perú, ed. Facsimilar, 1966.

Moreno Cebrián, Alfredo, El corregidor de indios y la economía peruana del siglo XVIII, Madrid, CSIC, 1977.

O’Phelan Godoy, Scarlett, Un siglo de rebeliones anticoloniales: Perú y Bolivia, 17001793, Cusco, Centro de Estudios Rurales Andinos "Bartolomé de Las Casas", 1988.

Peralta, Víctor, En defensa de la autoridad. Política y cultura bajo el gobierno del virrey Abascal (1806-1816), Madrid, CSIC, 2002.

Peralta, Víctor, Patrones, clientes y amigos. El poder burocrático indiano en la España del siglo XVIII, Madrid, CSIC, 2006.

Peset, Mariano, La enseñaza del derecho y la legislación sobre Universidades durante el reinado de Fernando VII (1808-1833), Madrid, Instituto Nacional de Estudios Jurídicos, Anuario de Historia del Derecho Español, 1968.

Peset, Mariano, La universidad española (siglos XVIII y XIX). Despotismo ilustrado y revolución liberal, Madrid, Taurus, 1974.

Peset, José Luis y Peset, Mariano, Carlos IV y la Universidad de Salamanca, Madrid, CSIC, 1983.

Ponce Sanginés, Carlos, El conato revolucionario referente al proceso seguido a Aguilar, Ubalde y otros. Recopilación histórica de Carlos, La Paz, Sesquicentenario de la Republica, Ediciones de la Casa Municipal de la Cultura "Franz Tamayo", 1975.

Puente Brunke, José de la, José Baquíjano y Carrillo, Lima, Editorial Brasa, 1995.

Rama, Angel, The Lettered City, Durham and London, Duke University Press, 1996: 18-19.

Representación que hace D. Jayme Bausate y Mesa, Autor del Diario Curioso, Erudito, Economico, y Comercial de Lima en el Reyno del Peru. A la Magestad del Señor D. Carlos IV, Lima, 1791.

Real Academia Española, Diccionario de la lengua castellana. 1737, 1780, 1791 y 1803, http://buscon.rae.es/ 
Riva-Agüero, José de la, "Don José Baquíjano y Carillo", Obras completas, Lima, Pontificia Universidad Católica del Perú, tomo 7, 1971:17-109.

Rodríguez O., Jaime E, The Independence of Spanish America, Cambridge, UK y Nueva York, Cambridge University Press, 1998.

Rodríguez Garrido, José Antonio, "Sermón barroco y poder colonial: La oración panegírica al apóstol Santiago de Espinosa Medrano", Sonia Rose (ed.), Discurso colonial hispanoamericano, Amsterdam, Atlanta, GA, Rodopi, 1992: 115-129.

Rodríguez Garrido, José Antonio, "La voz de las repúblicas: poesía y poder en la Lima de inicios del XVIII", José Antonio Mazzotti (ed.), Agencias criollas. La ambigüedad colonial en las letras hispanoamericanas, Pittsburgh, Instituto Internacional de Literatura Iberoamericana, 2000: 249-265.

Romero, Fernando, Rodríguez de Mendoza: hombre de lucha, Lima, Editorial Arica, 1973.

Rosas, Claudia, "El miedo a la revolución. Rumores y temores desatados por la Revolución Francesa en el Perú, 1790-1800”, Claudia Rosas (ed.), El miedo en el Perú. Siglos XVI al XX, Lima, Pontificia Universidad Católica del Perú, Fondo Editorial, 2005: 139-166.

Rosas, Claudia, Del trono a la guillotina. El impacto de la Revolución Francesa en el Perú (1789-1808), Lima, IFEA, Embajada de Francia, Fondo Editorial de la PUCP, 2006.

Sánchez Hita, Beatriz, Juan Antonio Olavarrieta/José Joaquín Clararrosa: periodista ilustrado. Aproximación biográfica y estudio del Semanario Crítico (Lima 1791) y del Diario de Cádiz (1796), Cádiz, Ayuntamiento de Cádiz, 2009.

Seoane, María Cruz, Oratoria y periodismo en la España del siglo XIX, Madrid, Castalia, 1977.

Semanario Crítico, Lima, 1791.

Spell, Jefferson, Rousseau in the Spanish World before 1833: A Study in FrancoSpanish Literary Relations, Austin, The University of Texas Press, 1938.

Tate Lanning, John, Academic Culture in the Spanish Colonies, Port Washington, NY, Kennikat Press, 1971.

Velázquez, Marcel (ed.), La república de papel: politica e imaginación social en la prensa peruana del siglo XIX, Lima, Universidad de Ciencias y Humanidades, Fondo Editorial, 2009.

Viqueira, Juan Pedro, Relajados o reprimidos?: diversiones públicas y vida social en la Ciudad de México durante el Siglo de las Luces, México, Fondo de Cultura Económica, 1987. 
Voltaire, François-Marie Arouet de, "Eloquence", Encyclopédie methódique par ordre des matières, vol. 5., 1755, http://www.hti.umich.edu/d/did/index.html (url no disponible).

Walker, Charles, Smoldering Ashes: Cuzco and the Creation of Republican Peru, 1780-1840, Durham, Duke University Press, 1999.

Fecha de recepción: 15/03/2011

Fecha de aceptación: 3/07/2012

\section{From Word to Action: Orators, Editors, Lawyers, and Conspirators in the Viceroyalty of Peru, 1780-1808}

This article analyzes the transformation of men of letters into political actors in the Viceroyalty of Peru in the years 1780-1808. It aims to contribute to the discussion on the rise of liberalism in the Spanish world. A key aspect in this process that has been insufficiently studied in the historiography on this topic was the emergence of new political actors during the first liberal era of the Cortes de Cádiz (1810-1814). This was not a sudden phenomenon, but the consequence of a long process of Bourbon reforms, during which the crown promoted the rise of a new kind of orators, writers, and lawyers. They were expected to reform the administration and modernize traditions. What the crown did not foresee was that these same individuals could rise to express their individual voices in public, criticize different forms of government, and imagine new social orders that would bring them to power.

Key Words: Peru; Spain; Enlightenment; Men of letters; Politics. 